\title{
ОПЫТ СОСТАВЛЕНИЯ МАШИННЫХ КАРТ РЕЛЬЕФА КОРЕННЫХ ПОРОД И ПЛЕЙТОЦЕНОВОГО ПОКРОВА ЭСТОНИИ
}

В последние годы в изучении рельефа коренных пород Эстонской ССР достигнуто немало результатов. Составленные схемы отдельных природных районов и республики в целом (Таваст, Раукас, 1982) вполне пригодны для проведения различных прикладных работ, но их трудно использовать для палеогеографических исследований разного рода. Нынешняя картина древнего рельефа не соответствует истинному рельефу в прошлые геологические эпохи, главным образом ввиду неравномерного и довольно интенсивного неотектонического поднятия территории. Если нам нужно реконструировать рельеф поверхности для определенного этапа геологического развития, например для начала плейстоцена или голоцена, то необходимо знать, насколько эта поверхность соответственно поднималась или опускалась в течение плейстоцена или голоцена.

Сошлемся еще раз на ранее составленные карты рельефа коренных пород (Таваст, Раукас, 1982 и др.). Все они показывают нынешнее положение рельефа, который является результатом влияния различных геологических процессов, в том числе длительной денудации, экзарации четвертичных ледников, неотектонических движений земной коры и др. Если бы нам удалось составить карту коренного рельефа с учетом дифференцированных неотектонических движений, то можно было бы более точно установить степень влияния подстилающей поверхности на движение и динамику ледника и на формирование различных ледниковых форм рельефа.

Например, карта рельефа позднего плейстоцена (сразу после окончательной деградации ледника с территории республики) помогла бы выяснить развитие гидрографической сети, указать пути течения талых вод и расположение береговых линий древних озер и т. д. При составлении таких усовершенствованных карт мы использовали методику, разработанную в секторе гидрогеологии Института геологии АН ЭССР для автоматизированной обработки региональной гидрогеологической информации, которую реализовали на ЭВМ типа ЕС.*

Машинная карта поля представляет собой матрицу, элементы которой отпечатаны по регулярной сети в виде алфавитно-цифровых символов. Машинные координаты, отпечатанные по краям карты, связаны с географическими координатами однозначно при помощи переходных коэффициентов. При машинном картировании нерегулярно расположенных точек производится восстановление поля во всех элементарных

* Валлнер Л. К., Ныгар П. Э., Улла Э. Ю., Юрима М. Х. Отчет по теме: «Разработать гидрогеологическую модель территории Эстонии и выдать на ее основе Госмелиоводхозу и Эстонгеологии рекомендации по рациональному использованию и охране подземных вод в республике». Рукопись в фонде Института геологии АН
ЭССР, 1979. 
точках карты. Для этого используется метод взвешенного скользящего круга. Каждая машинная карта состоит из трех частей: а) карта восстановленного сглаженного поля; б) карта исходного материала; в) экспликационная таблица. В последней приводится список исходного материала с координатами, список использованных символов с соответствующими им диапазонами поля и сводная таблица статистики по машинной карте.

В качестве исходных данных авторы использовали информацию о 734 буровых скважинах, расположенных более или менее равномерно по всей изученной территории. В квадрате $5 \times 5$ км находится одна скважина, которая является репрезентативной для данной территории. Обязательно отмечали скважину, наиболее точно характеризующую положение рельефа коренных пород. Машинная карта была составлена в масштабе 1:500000, но, в принципе, масштаб может быть любым. Древние речные долины и ложбины выпахивания не были учтены, так как для восстановления поля между заданными значениями наблюдаемых точек использовали метод взвешенного скользящего круга, который позволяет составить машинные карты только в случае, если величина изучаемого поля изменяется по площади плавно, т. е. использованная методика не позволяет нарисовать линейные формы рельефа.

Мы решили составить карту рельефа коренных пород для периода около 10500 лет назад, когда на территории Эстонии распространилась третья трансгрессивная фаза Балтийского ледникового озера. Как известно, береговые формы этой фазы Балтийского ледникового озера широко распространены, в рельефе они четко выражены и хорошо изучены (Кессел, 1975; Kessel, Raukas, 1979; Кессел, Раукас, 1982 и др.). К тому же береговые образования этой фазы надежно коррелируются с одновозрастными береговыми образованиями в Латвийской и Литовской ССР (Вейнбергс и др., 1974; Gudelis, 1979).

Чтобы получить поправку неотектонического поднятия для нанесения на карту, мы использовали схему береговых образований отмеченной выше фазы Балтийского ледникового озера с изобазами поднятия по Әстонской (Kessel, Raukas, 1979; Кессел, Раукас, 1982) и Латвийской CCP (Veinbergs, 1979) (рис. 1). Для получения сравнимых данных неотектонического поднятия возвышенной части территории вне акватории Балтийского ледникового озера был использован метод параллельных линий. Весь материал наносили на карту (масштаб 1:200000), затем для каждой из 734 точек определяли поправку неотектонического поднятия.

Мы исходили из предположения, что на рассматриваемой территории за позднеледниковое и голоценовое время не было существенных локальных различий в неотектонических движениях, т. е., если и имели место отдельные блоковые движения, то разница в их скорости была незначительной, что доказано изучением практически всех мелких куполовидных поднятий в пределах республики (Вахер, Таваст, 1979; Таваст, Раукас, 1982).

Путем машинного картирования были составлены две карты. На одной из них изобразили наблюдаемые точки, на основании которых и было выполнено картирование, а на другой карте в виде мозаики из различных символов показали значения изучаемого поля. Каждый символ отражает определенный, ранее выбранный диапазон. Если диапазоны символов выбраны удачно, то по символьной карте легко и надежно можно вычертить наглядные изолинии значений поля.

Диапазоны для наших карт были выбраны таким образом, что в районах с более расчлененным рельефом изолинии можно было нарисовать через 20 или 40 м, а в районах с более спокойным рельефом через 5 м, обычно через 10 м. В задачу данного сообщения не входит 


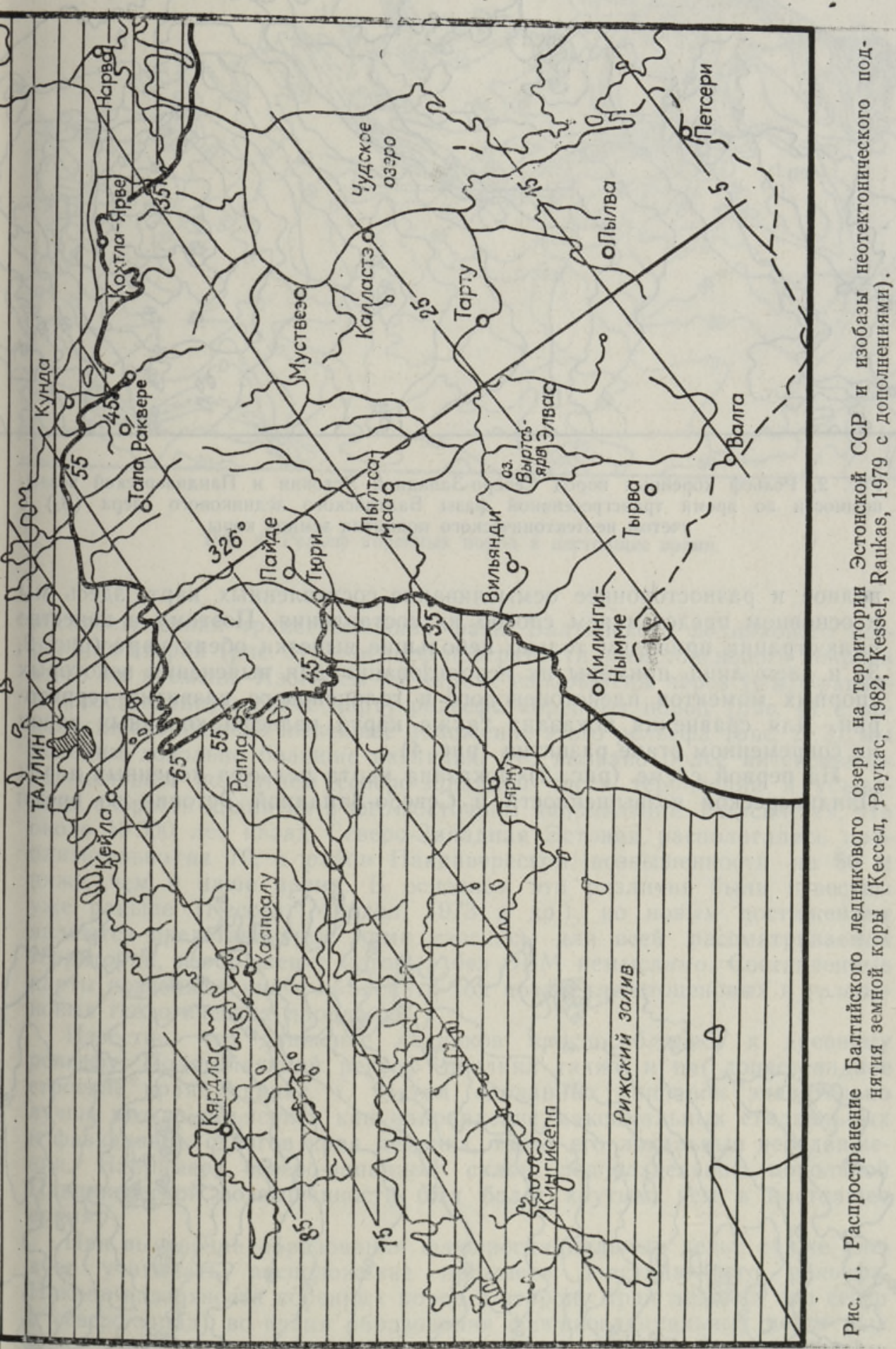




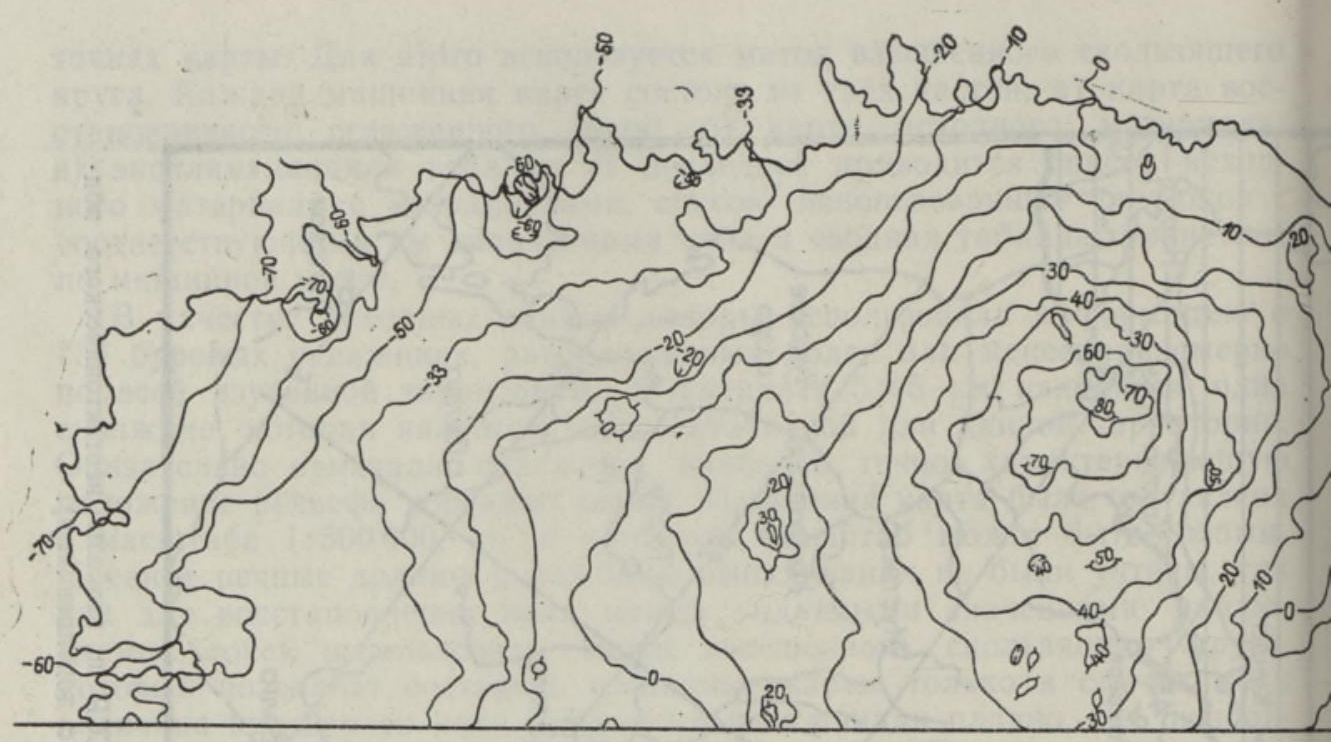

Рис. 2. Рельеф коренных пород Северо-Западной Эстонии и Пандивереской возвышенности во время трансгрессивной фазы Балтийского ледникового озера ( $\left(\mathrm{B}_{3}\right) \mathrm{c}$ учетом неотектонического поднятия земной коры.

полное и разностороннее осмысливание составленных карт, здесь мы в основном представляем способ их составления. Поэтому в качестве иллюстрации приводим только небольшие вырезки обеих карт (рис. 2, 3) и даем лишь примеры их использования для выяснения некоторых спорных моментов плейстоценового и голоценового развития территории. Для сравнения показана также карта рельефа коренных пород на современном этапе развития (рис. 4).

На первой схеме (рис. 2) показана карта рельефа коренных пород Пандивереской возвышенности и Северо-Западной Эстонии во время

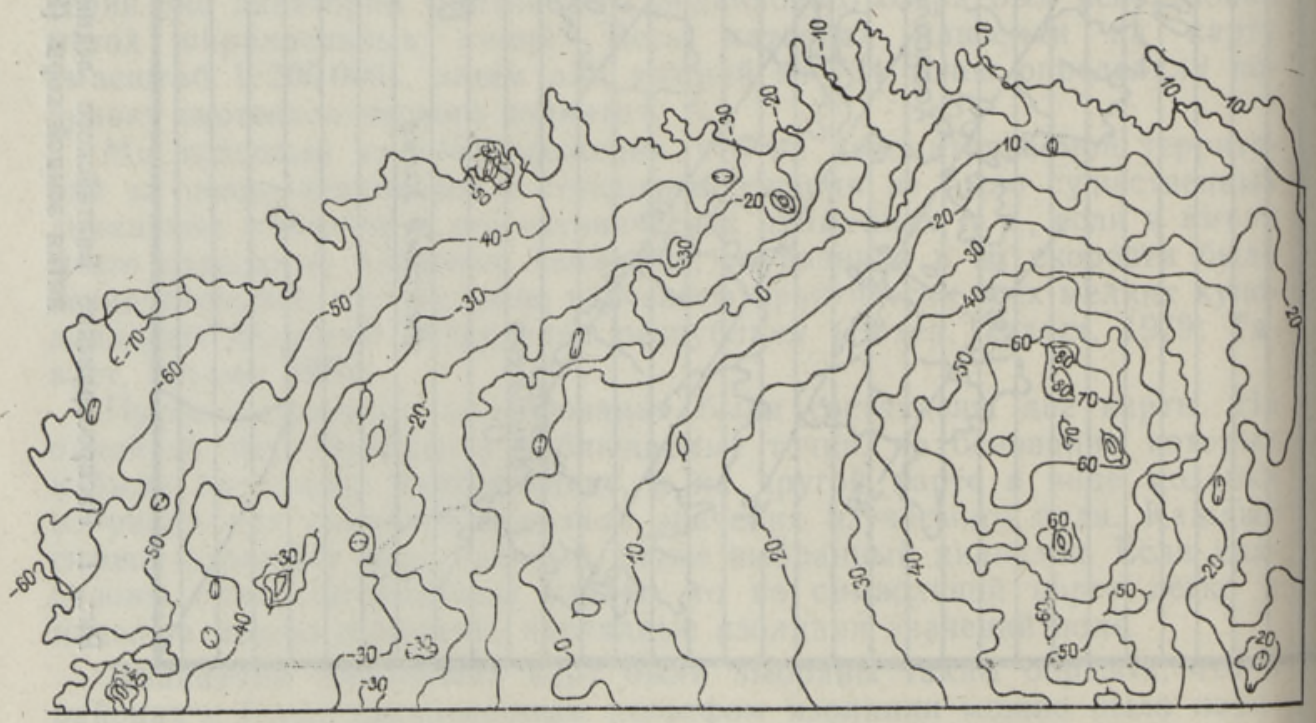

Рис. 3. Плейстоценовый рельеф во время фазы $\mathrm{B}_{3}$. 


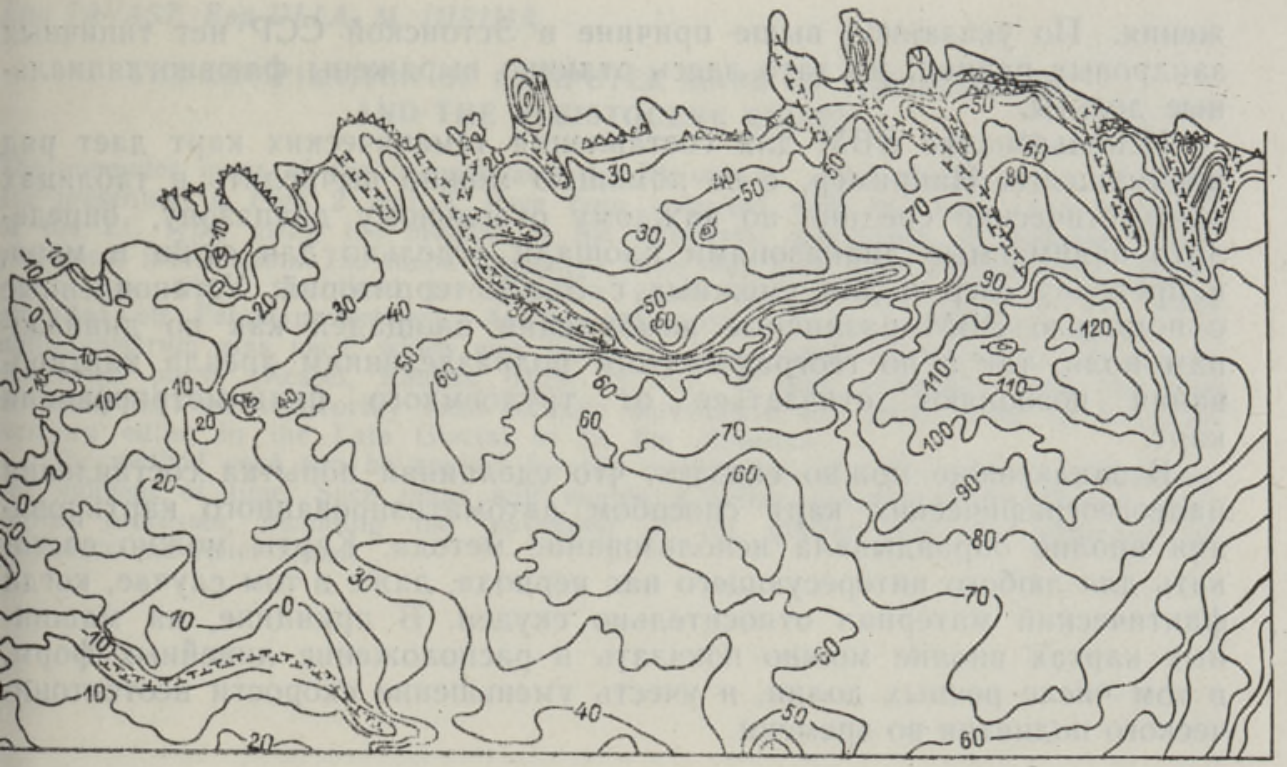

Рис. 4. Рельеф коренных пород в настоящее время.

распространения трансгрессивной фазы Балтийского ледникового озера, а на второй (рис. 3) - рельеф поверхности плейстоценового покрова этого же времени. Изогипсы на картах изображены через 10 м. Сравнивая составленную ранее карту рельефа коренных пород (рис. 4) с новой, где изображено нынешнее положение этого рельефа (рис. 2, 3), мы находим довольно большие различия, что вызвано более интенсивным голоценовым поднятием северо-западной части территории и убыванием скорости поднятия в юго-восточном направлении. Выясняется, что около 10500 лет назад Северо-Западная Әстония располагалась приблизительно на 70 , а район Пандивереской возвышенности на 50 м ниже, чем в наше время. В основном эти различия были известны уже раньше (Кессел, Мийдел, 1973 и др.), но новым достижением являются представленные нами изогипсы для всей рассматриваемой территории, изображение которых без ЭВМ немыслимо. Составленные карты позволяют иначе объяснить ход позднеплейстоценовых и голоценовых геологических процессов.

Известно, что движение ледников приспособлялось к древнему рельефу. Подстилающий рельеф повлиял также и на лопастевидное строение края ледника. С учетом сделанных поправок значительно лучше можно объяснить как направление максимальных стадиальных и фазиальных сдвигов края ледника, так и его локальные передвижения. Например, северо-западный склон ледораздельной цокольной Пандивереской возвышенности был более. крутым, чем в настоящее время.

При выяснении образования флювиогляциальных дельт также следует учитывать расположение прежнего подстилающего рельефа. Наклон поверхности коренных пород в сторону края ледника (на север и северо-запад) во время образования флювиогляциальных дельт был более значительным, чем сейчас в коренном рельефе. Это обстоятельство создало благоприятные условия для формирования крупных подпруженных краем ледника и древним рельефом озерноледниковых бассейнов (Раукас и. др., 1971), где накапливались дельтовые отло- 
жения. По указанной выше причине в Эстонской ССР нет типичных зандровых равнин, но зато здесь отлично выражены флювиогляциальные дельты.

Использование ЭВМ для составления тематических карт дает ряд преимуществ. Например, с ее помощью можно вычислить в таблицах арифметические средние по каждому отдельному диапазону, определить занимаемые диапазонами площади отдельно для суши и моря, в пределах озер и для смежных с ЭССР территорий. Установленные с помощью ЭВМ различные комбичации площадей как по диапазонам поля, так и по географическим подразделениям ареала картирования позволяют отказаться от трудоемкого планиметрирования карт.

В заключение можно сказать, что сделанная попытка составления палеогеографических карт способом автоматизированного картирования вполне оправдывала использование метода. Карты можно составить для любого интересующего нас периода, даже в том случае, когда фактический материал относительно скуден. В принципе, на машинных картах вполне можно показать и расположенне линейных форм, в том числе речных долин, и учесть уменьшение скорости неотектонического поднятия во времени.

\section{ЛИТ Е РА Т У А}

Baxep P., Таваст Э. Вопросы формирования рельефа коренных пород Эстонин. В кн.: Проблемы унаследованности тектонических структур в Прибалтике и Белоруссин. Таллин, 1979, 92-102.

Вейнберес И., Гринберес Э., Даниланс И., Ульст В. Поздне- и послеледниковая история Балтики, по материалам изучения Латвийского побережья. - Baltica, $1974,89-93$.

Кессел X. Я. Краткий обзор стратиграфии верхнеплейстоценовых и голоценовых отложений Балтийского моря в Эстонии. - Инф. бюлл. № 3. М., 1975, 54-63.

Кессел X., Мийдел A. О поздне- и послеледниковых движениях земной коры на территорин Эстонии. - Изв. АН ЭССР. Хим. Геол., 1973, 22, 257-264.

Кессел Х. Я., Раукас А. В. О геологическом развитии Балтийского моря в позднеледниковое время по материалам Восточной Прибалтики. - В кн.: Peribaltikum. t. II. Ossolineum, 1982, 131-143.

Раукас А. В., Ряхни Э. Э., Мийdе. А. М. Краевые ледниковые образования Северной Эстонин. Таллин, 1971.

Таваст Э. Х., Раукас А. В. Рельеф коренных пород Эстонии. Таллин, 1982.

Gudelis, $V$. The Quaternary history of the Baltic. The Eastern part. - Acta Univ. Upsala Symp. Univ. Upsala Ann. Quing. Cel., 1979, 1, 29-40.

Kessel, H., Raukas, A. The Quaternary history of the Baltic. Estonia. - Acta Univ. Upsala Symp. Univ. Upsala. Ann. Quing. Cel., 1979, 1, 127-146.

Veinbergs, I. The Quaternary history of the Baltic, Latvia. - Acta Univ. Upsala Symp. Univ. Upsala Ann. Quing. Cel., 1979, 1, 145-157.

Ннститут геологии

Академии наук Эстонской ССР
Поступила в редакцию 11/IV 1984

\section{Elvi TAVAST, Epp ULLA, M. JORIMA}

\section{ALUSPOHJA JA PLEISTOTSEENI RELJEEFI MASINAKAARTIDE KOOSTAMISEST}

Aluspõhja ja pleistotseeni reljeefi masinakaardid, mille näited on toodud joon. 2 ja 3 , on koostatud EC tüüpi arvutil, kasutades regionaalse hüdrogeoloogilise informatsiooni automaattöötluse metoodikat. Kaardid puudutavad aega ligikaudu 10500 aastat tagasi, kui Eesti alal laius Balti jääpaisjärve kolmas transgressiivne faas. Neotektoonilise kerke arvutamiseks on kasutatud nimetatud faasi rannamoodustiste alusel koostatud tõususpektrit (Kessel, Raukas, 1979 jt.). On lähtutud eeldusest, et Eesti alal märkimisväärseid lokaalseid tektoonilisi liikumisi hilisjääajal ja holotseenis ei toimunud.

Kasutatud metoodika abil saab paleoreljeefi kaarte koostada igasuguse ajamomendi kohta. Niisugused kaardid vōimaldavad paremini selgitada mitmeid geoloogilisi protsesse, sealhulgas näidata liustiku liikumist ja setete ning pinnavormide kujunemist. 


\section{THE COMPILATION OF COMPUTER MAPS OF THE BEDROCK AND THE PLEISTOCENE RELIEF}

The computer maps of the bedrock and the Pleistocene relief, the examples of which
are presented in Figs 2 and 3 . of the EC type, using the method of the automatic with the help of a computer geological information. The maps concern a time that took processing of regional hydroyears ago, when the third transgressive the that took place approximately 10500 prevailed on Estonian territory. At the calculation of Baltic Ice-Dammed Lake uplift spectrum was used, which was based mentioned phase (Kessel, Raukas, 1979, et al.) It was formations of the abovesumption that no noteworthy local tectonic et al.). It was proceeded from the preterritory either in the Late Glacial or in the Holocene taken place on Estonian

The method used can be applied for the Holocene.

any moment of time. Such maps will enable a better el paleorelief maps covering logical processes, including the movement of the glter elucidation of different geosediments and relief forms. 